\title{
Brassinosteroids and Plant Responses to Heavy Metal Stress. An Overview
}

\author{
Miriam Núñez Vázquez , Yanelis Reyes Guerrero, Lisbel Martínez González, \\ Walfredo Torres de la Noval \\ Department of Plant Physiology and Biochemistry, National Institute of Agricultural Sciences, \\ San José de las Lajas, Cuba \\ Email: *mnunez@inca.edu.cu
}

Received June 1, 2013; revised July 4, 2013; accepted July 11, 2013

Copyright (C) 2013 Miriam Núñez Vázquez et al. This is an open access article distributed under the Creative Commons Attribution License, which permits unrestricted use, distribution, and reproduction in any medium, provided the original work is properly cited.

\begin{abstract}
Soil contamination with heavy metals has become a world-wide problem, leading to the loss in agricultural productivity. Plants have a remarkable ability to take up and accumulate heavy metals from their external environment and it is well known that high levels of heavy metals affect different physiological and metabolic processes. Brassinosteroids are considered as the sixth class of plant hormones and they are essential for plant growth and development. These compounds are able of inducing abiotic stress tolerance in plants. In this paper, information about brassinosteroids and plant responses to heavy metal stress is reviewed.
\end{abstract}

Keywords: Heavy Metal Stress; Brassinosteroids; Tolerance

\section{Introduction}

Soil contamination with heavy metals has become a world-wide problem, leading to the loss in agricultural productivity and hazardous health effects as they become a part of the food chain [1]. However, their availability in the soil is determined by natural processes, especially the lithogenic and pedogenic ones, and by anthropogenic factors [2]. Plants have a remarkable ability to take up and accumulate heavy metals from their external environment and it is well known that some of these metals such as $\mathrm{Cu}, \mathrm{Zn}, \mathrm{Mn}, \mathrm{Fe}$ are required for normal plant growth and development at trace levels [3], since they are structural and catalytic components of proteins and enzymes. However, high concentrations of them and others such as $\mathrm{Al}, \mathrm{Cd}, \mathrm{Cr}, \mathrm{Pb}$ affect different physiological and metabolic processes at cellular and organism levels.

Toxicity mechanisms include the blockade of functional groups of important molecules, e.g. enzymes, polynucleotides, transport systems for essential nutrients and ions, displacement and/or substitution of essential ions from cellular sites, denaturation and inactivation of enzymes, and disruption of cell and organellar membrane integrity [4].

Heavy metal toxicity can elicit a variety of adaptive

"Corresponding author. responses in plants. These responses are based on mechanisms that lowering metal uptake and accumulation by plants. A common mechanism for heavy metal detoxification is the chelation of the metal ion by a ligand. Such ligands include organic acids, amino acids, peptides and polypeptides. Peptide ligands include the phytochelatins (PC), which detoxifies intracellular metals by binding them through thiolate coordination [4].

Plant hormones such as auxins (indole-3-acetic acid, IAA), abscisic acid (ABA) and brassinosteroids (BRs) have been recently found to work as vital components of stress management. Auxins have been observed to ameliorate the intensity of various stresses such as salinity, drought [5], chilling [6], heat and heavy metal stress [7]. Similarly, ABA triggers plant responses to adverse environmental stimuli [8]. Enhanced synthesis of PC contents by exogenous ABA has been reported in Prosopis juliflora under $\mathrm{Cu}, \mathrm{Zn}$ and $\mathrm{Cd}$ stress [9].

BRs are steroidal hormones which play a critical role in a range of developmental processes and they have also been implicated in plant responses to abiotic stress. Their ability to improve antioxidant system by elevating the activities and levels of enzymatic and non-enzymatic antioxidants has made them a favorite tool to increase resistance potential of important agricultural crops against various abiotic stresses such as heavy metal excess 
$[10,11]$.

\section{Brassinosteroids and Plant Responses to Heavy Metal Stress}

BRs are able to regulate the uptake of ions into the plant cells and can be used to reduce the accumulation of heavy metals [12], because they can reduce the metal uptake by roots [13] and can also stimulate the synthesis of some ligands such as the phytochelatins, which are combined with metal ion $[14,15]$. They also increase the activities of some antioxidant enzymes detoxifying the increased production of reactive oxygen species (ROS) generated by heavy metal stress [16-18] and so exogenous applications of BRs improve the growth and metabolic activity in plants under heavy metal stress.

\subsection{Responses to Copper (Cu) Stress}

Copper is an essential transition metal required for normal plant growth and development at trace levels $[3,19]$. It is an indispensable component of diverse plant metabolic reactions, such as a structural element in regulatory proteins and its participation in photosynthetic electron transport, mitochondrial respiration, oxidative stress response, cell wall metabolism and hormone signaling are well established [20]. Among pollutants of agricultural soils, $\mathrm{Cu}$ has become increasingly hazardous due to its involvement in fungicides, fertilizers and pesticides [21].

However, excess of $\mathrm{Cu}$ metal catalyzes the formation of ROS $[22,23]$. These ROS are highly toxic and oxidize important macromolecules such as nucleic acids, proteins and lipids, thereby disturbing cell stability and membrane permeability [24,25]. Also, the reduced shoot and root growth, decline in photosynthetic pigment formation have been observed in plants under $\mathrm{Cu}$ stress [26].

Effects of exogenous applications of BRs (24-epibrassinolide, EBL) have been studied on mustard and radish plants under copper stress. Sharma and Bhardwaj (2007) observed an improvement in the shoot emergence and plant biomass production under $\mathrm{Cu}$ stress when mustard seeds were soaked for 8 hours in EBL $\left(10^{-7}\right.$, $10^{-9}$ and $10^{-11} \mathrm{M}$ ) solutions. In addition, EBL blocked $\mathrm{Cu}$ metal uptake and accumulation in these plants [12].

In radish seedlings, EBL-treated seeds $\left(10^{-7} \mathrm{M}\right)$ showed a reduced copper toxicity by stimulating the root and shoot growth [15]. This growth response was associated with enhanced IAA and ABA concentrations, lowered oxidative stress (a major increase of antioxidant enzyme activities, a major decrease of MDA and increased contents of antioxidant metabolites such as proline, ascorbic acid and total phenols) and increased phytochelatin content in the seedlings. Effects of EBL on antioxidant capacity and free radical scavenging activity of radish seedlings were also studied [27].

\subsection{Responses to Nickel (Ni) Stress}

Nickel is one of the most abundant heavy metal contaminants of the environment due to its release from mining and smelting practices. It is classified as an essential element for plant growth [28]. However, at higher concentrations, nickel is an important environmental pollutant. $\mathrm{Ni}^{2+}$ ions bind to proteins and lipids such as specific sub-sequences of histones [29] and induce oxidative damage. Excess of nickel affects chlorophyll biosynthesis, since it affects both the synthesis of $\delta$-aminolevulinic acid and protochlorophyllide reductase complex [30]. $\mathrm{Ni}^{2+}$ also replaces the $\mathrm{Mg}^{2+}$ ion of chlorophyll pigment [31], causes the inhibition of enzymes of chlorophyll biosynthesis [32] and stimulates chlorophyllase [33], ultimately leading to a decline in the level of chlorophyll pigment. Nickel also causes a significant inhibition in the activities of enzymes associated to carbon fixation in plants [34].

EBL and 28-homobrassinolide (HBL) protect plants under nickel stress conditions. Mustard (Brassica juncea) plants treated with $\mathrm{Ni}_{2} \mathrm{Cl}$ and later, with a HBL foliar spray showed no nickel toxic effect on growth, net photosynthetic rate, chlorophyll content and nitrate reductase and carbonic anhydrase activities. Moreover, HBL treatment stimulated the activities of some antioxidant enzymes such as peroxidases and catalases and the level of proline [35]. Similar results were obtained in this specie by Ali et al. (2008) using EBL foliar spray and by Sharma et al. (2008) with HBL seed treatment for 8 hours $[36,37]$. EBL enhanced the level of antioxidant system (superoxide dismutase, catalase, peroxidase and glutathione reductase and proline), under stress conditions. The influence of EBL on antioxidant system, at least in part, increased the tolerance of mustard plants to $\mathrm{NiCl}_{2}$ stress and thus protected the photosynthetic machinery and the plant growth.

Recently, a research was performed in which various concentrations of the isolated EBL from Brassica juncea leaves were given as pre-sowing treatment to the seeds of this same species for $8 \mathrm{~h}$. The pre-treated seeds were subjected to nickel stress. Results showed that pre-treatment of isolated EBL lowered the Ni ion uptake in plants and improved growth. The amelioration of Ni toxicity was also observed by the activities of antioxidant enzymes [28].

The results described above associate the BR protection to Ni stress in plants, particularly in mustard, with the lowering of oxidative stress, because of the increase of antioxidant enzyme activities and the proline level. It may explain the protection to photosynthetic machinery and the plant growth stimulation.

\subsection{Responses to Cadmium (Cd) Stress}

$\mathrm{Cd}$ is not an essential nutrient and it is one of the heavy 
metals that are known to generate toxicity even at a very low concentration. It accumulates in plants during growth in edible parts, thereby, endangering crop yield and their quality. This causes a potential hazard to human and animal health. $\mathrm{Cd}$ is known to cause enzyme inactivation and damages cells by acting as antimetabolite or forms precipitates or chelates with a number of essential metabolites [38]. Cd inhibits plant growth [39], retards the biosynthesis of chlorophyll [40], alters water balance [41], decreases the activities of various enzymes [42], stimulates stomatal closure [43] and controls photosynthesis $[34,44]$. Cadmium stress reduces the uptake of essential mineral nutrients and also affects the activity of ATPase of plasma membrane [45].

Various researchers have demonstrated that BRs reduce the adverse effects induced by Cd stress in plants. Thus, Janeczko et al. (2005) found that EBL reduced the toxic effect of $\mathrm{Cd}$ on photochemical processes by diminishing the damage of photochemical reaction centers and the activity of $\mathrm{O}_{2}$ evolving centers as well as maintaining efficient photosynthetic electron transport [46]. Probably, the effectiveness of the protective action of EBL increases in older tissue, which is more susceptible to damage by Cd. Later, Anuradha and Rao (2009) reported that EBL stimulated photosynthetic activity in radish plants under Cd stress [11].

On the other hand, EBL foliar spray enhanced the level of antioxidant system (superoxide dismutase, catalase, peroxidase and glutathione reductase, and proline) of bean plants under Cd stress conditions [17]. This author suggested that the elevated level of antioxidant system, at least in part, increased the tolerance of bean plants to $\mathrm{CdCl}_{2}$ stress, thus protected the photosynthetic machinery and the plant growth. Similar results had been reported in mustard [47] and chickpea [16] plants using EBL and HBL, respectively.

The application of BRs (EBL and HBL) improved the chlorophyll content and photosynthesis efficiency of $\mathrm{Cd}$ stressed tomato plants applied as shotgun approach [48]. Besides, BR treatment significantly increased the number of fruits, fruit yield and lycopene and $\beta$-carotene contents in the fruits from plants grown under $\mathrm{Cd}$ stress.

\subsection{Responses to Other Heavy Metal Stresses}

Zinc $(\mathrm{Zn})$ is an essential microelement, the second most abundant transition metal after iron (Fe) and plays a pivotal role in many metabolic reactions in plants $[49,50]$. However, high concentrations of $\mathrm{Zn}$ are toxic, induce structural disorders and cause functional impairment in plants. At organism level, $\mathrm{Zn}$ stress causes reduced rooting capacity, stunted growth, chlorosis and at cellular level alters mitotic activity [51,52], affects the membrane permeability, the electron transport chain, the uptake and translocation of nutrient elements $[53,54]$ and induces oxidative stress by promoting the generation of ROS. Since $\mathrm{Zn}$ is a non-redox metal, it cannot generate ROS directly through Haber-Weiss reactions, over production of ROS and occurrence of oxidative stress could be an indirect consequence of $\mathrm{Zn}$ toxicity.

Recently, Ramakrishna and Rao (2012) reported that the application of EBL significantly alleviated the zinc induced oxidative stress. EBL had a protective role on lipid peroxidation, protein oxidation and membrane integrity in radish seedlings [55]. This BR induced lowering of ROS levels, MDA and carbonyl levels could be attributed to the increased activities of ROS scavenging enzymes and the decreased activities of lipoxygenase (enzyme which catalyzes the oxygenation of polyunsaturated fatty acids into lipid hydroperoxides), and NADPH oxidase (enzyme which catalyzes the formation $\mathrm{O}^{2-}$ that is converted to more stable $\mathrm{H}_{2} \mathrm{O}_{2}$ via complex reaction). A similar response of $\mathrm{Zn}$ induced oxidative stress had been reported in Brassica juncea plants [56].

In lower organisms like the alga Chlorella vulgaris, Bajguz (2000) demonstrated that EBL blocked the heavy metals accumulation in the cells. The inhibitory effect on heavy metal accumulation was arranged in the following order: $\mathrm{Zn}>\mathrm{Cd}>\mathrm{Pb}>\mathrm{Cu}$ [57]. The author associated BR protection to heavy metal stress to EBL-induced $\mathrm{pH}$ increase in the medium, since lower $\mathrm{pH}$ increased the toxicity of heavy metals in C. vulgaris cells.

On the other hand, aluminum (Al) and chromium $(\mathrm{Cr})$ are not essential nutrients. Al toxicity is the major growth-limiting factor for crop cultivation on acidic soil [58] that generates oxidative stress indirectly, mediated by its influence on membrane lipids and other peroxidants such as iron [59]. Al ions are capable of binding with lipid components of the plasma membrane [60] causing the rigidification of plasma membrane [61] and to DNA [62], and therefore, impairs cell division [58]. Al is reported to inhibit the plant growth [63], mainly that of root $[64,65]$. Besides this, Al also alters water relations [41], reduces stomatal opening, decreases photosynthetic activity and causes chlorosis and necrosis of leaves [58].

Ali et al. (2008) reported that EBL or HBL treatment improved the response of mung bean seedlings to $\mathrm{Al}$ stress [66]. This response was associated to the ameliorated level of antioxidant system, suggesting that, at least in part, it was responsible for the development of resistance against $\mathrm{Al}$ stress in these seedlings. The increase in the degree of resistance due to the application of BRs was reflected in the improvement of plant growth, photosynthesis and related processes, in the presence of Al.

$\mathrm{Cr}$ metal pollution in the biosphere has increased sharply over the last few decades, mainly due to its anthropogenic release from leather, electroplating, catalytic manufacturing, chromic acid and refractory steel industries [67]. However, in nature, $\mathrm{Cr}$ is usually found in tri- 
valent (Cr III) and hexavalent (Cr VI) oxidation states, of which $\mathrm{Cr}$ (VI) is more phytotoxic, owing to its greater mobility. The entry of $\mathrm{Cr}$ into a plant system occurs through roots using the specialized uptake systems of essential metal ions (Fe, S), required for normal plant metabolism [67]. Reduced seed germination, disturbed nutrient balance, with decreased rate of photosynthesis, inactivation of Calvin cycle enzymes, and chloroplast disorganization have been documented in plants under $\mathrm{Cr}$ stress [67]. The oxidative stress under $\mathrm{Cr}$ excess is caused by the over production of ROS.

The significant influence of EBL on the synthesis of IAA, ABA and polyamines (PAs) of radish seedlings under $\mathrm{Cr}$ (VI) metal stress was demonstrated by Choudhary et al. (2011). EBL could enhance the synthesis of IAA in order to promote normal seedling growth under $\mathrm{Cr}$ (VI) metal stress. On the other hand it also slightly improved the production of ABA to increase $\mathrm{Cr}$ (VI) stress tolerance. Altered synthesis of PAs observed under the influence of EBL may be helpful in protecting the seedlings against $\mathrm{Cr}$ (VI) stress by enhancing one pool of PAs (putrescine and spermidine) and decreasing the other pool (cadaverine) [68]. Increased levels of antioxidants and antioxidant enzymes activities upon EBL application with Cr (VI) metal stress also indicate its significant effect on antioxidant system of radish plants. Similarly, reduced membrane damage, enhanced proline, photosynthetic pigments, sugars and radical scavenging activities also shows a major impact of EBL on radish seedling metabolism under Cr (VI) metal stress.

Earlier, Arora et al. (2010) had reported the effect of EBL treatment to regulate the diminution of $\mathrm{Cr}$ metal toxicity in mustard plants [69].

Besides, the interaction of EBL with lead $(\mathrm{Pb})$ on the growth of algae and ion accumulation in Chlorella vulgaris cells was studied by Bajguz (2000) [57] while the effect of BRs on oxidative stress generated by manganese stress in maize leaves was reported by Wang et al. (2009) [70].

\section{Concluding Remarks}

BRs reduced the heavy metal toxicity in plants. Firstly, this reduction was associated with lesser ion uptake and accumulation and with the increasing activity of ATPase, an enzyme responsible for acid secretion and changes in membrane level [57]. The proton pump generates an $\mathrm{H}^{+}$ electrochemical gradient and provides a driving force for the rapid ion fluxes required for the uptake of various nutrients such as $\mathrm{K}^{+}, \mathrm{Cl}^{-}, \mathrm{NO}_{3}^{-}$, amino acids and sucrose across the plasma membrane [71]. The regulation of $\mathrm{H}^{+}$-ATPase activity [72] not only allows nutrient uptake in plant cells but also controls water fluxes [73]. In addition to this, proton secretion induced by BRs has been reported too. This proton secretion was accompanied by an early hyperpolarization of the plasma membrane, indicating that proton pumps could be targets of BRs [74].

On the other hand, the lesser ion accumulation induced by BRs may be explained by the ability of these compounds to increase some ligands which form chelates with metal ion as, for example, phytochelatins [14]. Further, BRs have also influence on electrical properties of membranes and transport of ions by altering their permeability and structure, stability and activity of membrane enzymes.

All the above results confirmed that phytotoxicity from heavy metals is closely related to oxidative stress and so to the production of ROS in plants. An imbalance between ROS production and ROS scavenging leads to oxidative burst. ROS can react with nucleic acids, proteins and lipids and causes membrane damage and enzyme inactivation resulting in inhibition of plant growth [75]. In plants, removal of ROS and cellular homeostasis are governed by antioxidative enzymes such as superoxide dismutase (SOD), peroxidase (POD) and catalase (CAT) and the enzymes of ascorbate-glutathione cycle and various non-enzymatic antioxidants such as carotenoids, $\alpha$-tocopherol, proline, phenols, ascorbate and glutathione via scavenging and neutralization $[76,77]$.

The elevation in the activities of antioxidant enzymes by BRs is well documented and it is known that it is a gene regulated phenomenon. Cao et al. (2005) demonstrated on the basis of molecular, physiological and genetic approaches the elevation in antioxidant enzymes was the consequence of enhanced expression of det 2 gene, which enhanced the resistance to oxidative stress in Arabidopsis [78]. Similarly, Xia et al. (2009) reported that BRs-induced stress tolerance is associated with increased expression of genes encoding antioxidant enzymes such as SOD, CAT, POD, GR and APX in leaves of cucumber [79]. Various reports have also shown that the application of BRs modified antioxidant enzymes activities under other abiotic stresses such as water deficit [80], salinity [81], high temperature [82] and chilling [83].

Plant protection induced by BRs under heavy metal stress has been related to interactions of these steroidal hormones with other plant hormones such as IAA and ABA. Recently, Choudhary et al. (2012) reviewed the benefits of brassinosteroid crosstalk and they concluded that the versatile role of BRs may be attributed to multilayer interactions with other plant growth regulators affecting the post-transcriptional fate of the target response [84], although they pointed out that the mechanisms behind the pleiotropic action of BRs and the execution of BR-induced responses still remain poorly understood at this time.

So, the focus of future research should be to elucidate the mechanism by which BRs confer tolerance to heavy 
metal stress at cellular and molecular levels.

\section{REFERENCES}

[1] D. E. Salt, M. Blaylock, N. P. B. A. Kumar, V. Dushenkov, B. B. Ensley, I. Chet and I. Raskin, "Phytoremediation: A Novel Strategy for the Removal of Toxic Metals from the Environmental Using Plants," Biotechnology, Vol. 13, 1995, pp. 468-474. doi:10.1038/nbt0595-468

[2] S. Kevrešan, N. Petrovič, M. Popovič and M. Kandrač, "Effect of Heavy Metals on Nitrate and Protein Metabolism in Sugar Beet," Biologia Plantarum, Vol. 41, No. 2, 1998, pp. 235-240. doi:10.1023/A:1001818714922

[3] G. Bhakuni, B. K. Dube, P. Sinha and C. Chatterjee, "Copper Stress Affects Metabolism and Reproductive Yield of Chickpea," Journal of Plant Nutrition, Vol. 32, No. 4, 2009, pp. 703-711. doi: $10.1080 / 01904160902743258$

[4] A. Bajguz and S. Hayat, "Effects of Brassinosteroids on the Plant Responses to Environmental Stresses," Plant Physiology and Biochemistry, Vol. 47, No. 1, 2009, pp. 1-8. doi:10.1016/j.plaphy.2008.10.002

[5] M. Farooq, A. Wahid, N. Kobayashi, D. Fujita and S. M. A. Basra, "Plant Drought Stress: Effects, Mechanisms and Management," Agronomy for Sustainable Development, Vol. 29, No. 1, 2009, pp. 185-212. doi:10.1051/agro:2008021

[6] M. M. Posymk, M. Balabusta, M. Wieczorek, E. Sliwinska and K. M. Janas, "Melatonin Applied to Cucumber (Cucumis sativus L.) Seeds Improves Germination during Chilling Stress," Journal of Pineal Research, Vol. 46, No. 2, 2009, pp. 214-223. doi:10.1111/j.1600-079X.2008.00652.x

[7] C. O. Dimpka, A. Svatos, P. Dabrowska, A. Schmidt, W. Boland and E. Kothe, "Involvement of Siderophores in the Reduction of Metal-Induced Inhibition of Auxin Synthesis in Streptomyces spp.," Chemosphere, Vol. 74, No. 1, 2008, pp. 19-25.

doi:10.1016/j.chemosphere.2008.09.079

[8] T. Kellos, I. Timar, V. Szilagyi, G. Szalai, G. Galiba and G. Kocsy, "Stress Hormones and Abiotic Stresses Have Different Effects of Antioxidants in Maize Lines with Different Sensitivity," Plant Biology, Vol. 10, No. 5, 2008, pp. 563-572. doi:10.1111/j.1438-8677.2008.00071.x

[9] B. Usha, G. Venkataraman and A. Parida, "Heavy Metal and Abiotic Stress Inducible Metallothionein Isoforms from Prosopis juliflora (SW) D.C. Show Differences in Binding to Heavy Metals in Vitro," Molecular Genetics and Genomics, Vol. 281, No. 1, 2009, pp. 99-108. doi:10.1007/s00438-008-0398-2

[10] R. Bhardwaj, N. Arora and P. Sharma and H. K. Arora, "Effects of 28-Homobrassinolide on Seedling Growth, Lipid Peroxidation and Antioxidative Enzyme Activities under Nickel Stress in Seedlings of Zea mays L.," Asian Journal of Plant Sciences, Vol. 6, No. 5, 2007, pp. 765772. doi:10.3923/ajps.2007.765.772

[11] S. Anuradha and S. S. R. Rao, "Effect of 24-Epibrassino- lide on the Photosynthetic Activity of Radish Plants under Cadmium Stress," Photosynthetica, Vol. 47, No. 2, 2009, pp. 317-320. doi:10.1007/s11099-009-0050-3

[12] P. Sharma and R. Bhardwaj, "Effects of 24-Epibrassinolide on Growth and Metal Uptake in Brassica juncea L. under Copper Metal Stress," Acta Physiologiae Plantarum, Vol. 29, No. 3, 2007, pp. 259-263. doi:10.1007/s11738-007-0032-7

[13] V. A. Khripach, V. N. Zhabinskii and A. E. de Groot, "Brassinosteroids. A New Class of Plant Hormones," Academic Press, San Diego, 1999.

[14] A. Bajguz, "Brassinosteroids and Lead as Stimulators of Phytochelatins Synthesis in Chlorella vulgaris," Journal of Plant Physiology, Vol. 159, No. 3, 2002, pp. 321-324. doi:10.1078/0176-1617-00654

[15] S. P. Choudhary, R. Bhardwaj, B. D. Gupta, P. Dutt, R. K. Gupta, S. Biondi and M. Kanwar, "Epibrassinolide Induces Changes in Indole-3-Acetic Acid, Abscisic Acid and Polyamine Concentrations and Enhances Antioxidant Potential of Radish Seedlings under Copper Stress," Plant Physiology, Vol. 140, 2010, pp. 280-296.

[16] S. A. Hasan, S. Hayat, B. Ali and A. Ahmad, "28-Homobrassinolide Protects Chickpea (Cicer arietinum) from Cadmium Toxicity by Stimulating Antioxidants," Environmental Pollution, Vol. 151, No. 1, 2008, pp. 60-66. doi:10.1016/i.envpol.2007.03.006

[17] M. M. Rady, "Effect of 24-Epibrassinolide on Growth, Yield, Antioxidant System and Cadmium Content of Bean (Phaseolus vulgaris L.) Plants under Salinity and Cadmium Stress," Scientia Horticulturae, Vol. 129, No. 2, 2011, pp. 232-237. doi:10.1016/j.scienta.2011.03.035

[18] M. Yusuf, Q. Fariduddin and A. Ahmad, "24-Epibrassinolide Modulates Growth, Nodulation, Antioxidant System and Osmolyte in Tolerant and Sensitive Varieties of Vigna radiata under Different Levels of Nickel: A Shotgun Approach," Plant Physiology and Biochemistry. Vol. 57, 2012, pp. 143-153. doi:10.1016/j.plaphy.2012.05.004

[19] K. Mengel and E. A. Kirkby, "Principles of Plant Nutrition," 4th Edition, International Potash Institute, Basel, 1987.

[20] J. A. Raven, M. C. W. Evans and R. E. Korb, "The Role of Trace Metals in Photosynthetic Electron Transport in $\mathrm{O}_{2}$-Evolving Organisms," Photosynthesis Research, Vol. 60, No. 2-3, 1999, pp. 111-150. doi:10.1023/A:1006282714942

[21] L. M. Chen, C. C. Lin and C. H. Kao, "Copper Toxicity in Rice Seedlings: Changes in Antioxidative Enzyme Activities, $\mathrm{H}_{2} \mathrm{O}_{2}$ Level and Cell Wall Peroxidase Activity in Roots," Botanical Bulletin of Academy Sinica, Vol. 41, 2000, pp. 99-103.

[22] B. Halliwell, J. M. C Gutteridge and O. I. Aruoma, "The Deoxyribose Method: A Simple 'Test Tube' Assay for Determination of Rate Constants for Reactions of Hydroxyl Radical," Analytical Biochemistry, Vol. 165, No. 1, 1987, pp. 215-219. doi:10.1016/0003-2697(87)90222-3

[23] C. M. Luna, C. A. González and V. S. Trippi, "Oxidative Damage Caused by an Excess of Copper in Oat Leaves," Plant and Cell Physiology, Vol. 35, 1994, pp. 11-15.

[24] E. Lovaas, "Antioxidant and metal-chelating effects of 
polyamines". In: Sies H (ed) Advances in Pharmacology, Vol. 38, Antioxidants in Disease Mechanisms and Therapy. Academic Press, pp. 119-149, 1997.

[25] A. Schutzendubel and A. Polle, "Plant Responses to Abiotic Stresses: Heavy Metal-Induced Oxidative Stress and Protection by Mycorrhization," Journal of Experimental Botany, Vol. 53, No. 372, 2002, pp. 1351-1365. doi:10.1093/jexbot/53.372.1351

[26] A. M. Michaud, C. Chappellaz and P. Hinsinger, "Copper Phytotoxicity Affects Root Elongation and Iron Nutrition in Durum Wheat (Triticum turgidum Durum L.)," Plant and Soil, Vol. 310, No. 1-2, 2007, pp. 151-165. doi:10.1007/s11104-008-9642-0

[27] S. P. Choudhary, R. Bhardwaj, B. D.Gupta, P. Dutt, R. K. Gupta, M. Kanwar and S. Biondi, "Enhancing Effects of 24-Epibrassinolide and Putrescine on the Antioxidant Capacity and Free Radical Scavenging Activity of Raphanus sativus Seedlings under Cu Ion Stress," Acta Physiologiae Plantarum, Vol. 33, No. 4, 2011, pp. 13191333. doi:10.1007/s11738-010-0665-9

[28] M. K. Kanwar, R. Bhardwaj, S. P. Chowdhary, P. Arora, P. Sharma and S. Kumar, "Isolation and Characterization of 24-Epibrassinolide from Brassica juncea L. and Its Effects on Growth, Ni Ion Uptake, Antioxidant Defense of Brassica Plants and in Vitro Cytotoxicity," Acta Physiologiae Plantarum, Vol. 35, No. 4, 2013, pp. 13511362. doi:10.1007/s11738-012-1175-8

[29] W. Bal and K. S. Kasprzak, "Induction of Oxidative Damage by Carcinogenic Metal," Toxicology Letters, Vol. 127, No. 1-3, 2002, pp. 55-62. doi:10.1016/S0378-4274(01)00483-0

[30] A. K. Stobart, W. Griffits, L. Bukhari and A. Sherwood, "The Effect of $\mathrm{Cd}^{2+}$ on the Biosynthesis of Chlorophyll in Leaves of Barley," Physiologia Plantarum, Vol. 63, No. 3, 1985, pp. 293-298. doi:10.1111/j.1399-3054.1985.tb04268.x

[31] H. Kupper, F. Kupper and M. Spiller, "In Situ Detection of Metal Substituted Chlorophylls in Water Plants," Photosynthesis Research, Vol. 58, No. 2, 1998, pp. 123-133. doi:10.1023/A:1006132608181

[32] N. V. Shalygo, N. V. Kolensikova, V. V. Voronetskaya and N. G. Averina, "Effects of $\mathrm{Mn}^{2+}, \mathrm{Fe}^{2+}, \mathrm{Co}^{2+}$ and $\mathrm{Ni}^{2+}$ on Chlorophyll Accumulation and Early Stages of Chlorophyll Formation of Greening Barley Seedling," Russian Journal of Plant Physiology, Vol. 46, 1999, pp. 496-501.

[33] R. Abdel-Basset, A. A. Issa and M. S. Adam, "Chlorophyllase Activity: Effects of Heavy Metal and Calcium," Photosynthetica, Vol. 31, 1995, pp. 421-425.

[34] I. S. Sheoran, H. R. Signal and R. Singh, "Effect of Cadmium and Nickel on Photosynthesis and the Enzymes of the Photosynthetic Carbon Reduction Cycle in Pigeon Pea (Cajanus cajan L.)," Photosynthesis Research, Vol. 23, No. 3, 1990, pp. 345-351. doi:10.1007/BF00034865

[35] M. M. Alam, S. Hayat, B. Ali and A. Ahmad, "Effect of 28-Homobrassinolide Treatment on Nickel Toxicity in Brassica juncea," Photosynthetica, Vol. 45, No. 1, 2007, pp. 139-142. doi:10.1007/s11099-007-0022-4

[36] B. Ali, S. Hayat, Q. Fariduddin and A. Ahmad, "24-Epibrassinolide Protects against the Stress Generated by Sa- linity and Nickel in Brassica juncea," Chemosphere, Vol. 72, No. 9, 2008, pp. 1387-1392.

doi:10.1016/j.chemosphere.2008.04.012

[37] P. Sharma, R. Bhardwaj, N. Arora, H. K. Arora and A. Kumar, "Effects of 28-Homobrassinolide on Nickel Uptake, Protein Content and Antioxidative Defence System in Brassica juncea," Biologia Plantarum, Vol. 52, No. 4, 2008, pp. 767-770. doi:10.1007/s10535-008-0149-6

[38] S. Hayat, M. N. Alyemeni and S. A. Hasan, "Foliar Spray of Brassinosteroid Enhances Yield and Quality of Solanum lycopersicum under Cadmium Stress," Saudi Journal of Biological Sciences, Vol. 19, No. 3, 2012, pp. 325335.

[39] A. P. Pinto, A. M. Mota, A. de Varennes and F. C. Pinto, "Influence of Organic Matter on the Uptake of Cadmium, Zinc, Copper and Iron by Sorghum Plants," Science of the Total Environment, Vol. 326, No. 1-3, 2004, pp. 239-247. doi:10.1016/j.scitotenv.2004.01.004

[40] P. K. Singh and R. K. Tewari, "Cadmium Toxicity Induced Changes in Plant Water Relations and Oxidative Metabolism of Brassica juncea L. Plants," Journal of Environmental Biology, Vol. 24, No. 1, 2003, pp. 107-112.

[41] J. Barcelo and C. Poschenrieder, "Fast Root Growth Responses, Root Exudates and Internal Detoxification as Clues to the Mechanisms of Aluminium Toxicity and Resistance: A Review," Environmental and Experimental Botany, Vol. 48, No. 1, 2002, pp. 75-92. doi:10.1016/S0098-8472(02)00013-8

[42] A. Siedlecka, Z. Krupa, G. Samuelsson, G. Öquist and K. Gardeström, "Primary Carbon Metabolism in Phaseolus vulgaris Plants under $\mathrm{Cd} / \mathrm{Fe}$ Interaction," Plant Physiology and Biochemistry, Vol. 35, No. 12, 1997, pp. 951957.

[43] C. Poschenrieder, B. Gunse and J. Barcelo, "Influence of Cadmium on Water Relations, Stomatal Resistance, and Abscissic Acid Content in Expenditure Bean Leaves," Journal of Experimental Botany, Vol. 90, No. 4, 1989, pp. 1365-1371. doi:10.1104/pp.90.4.1365

[44] L. K. Chugh and S. K. Sawhney, "Photosynthetic Activities of Pisum sativum Seedling Grown in Presence of Cadmium," Plant Physiology and Biochemistry, Vol. 37, No. 4, 1999, pp. 297-303. doi:10.1016/S0981-9428(99)80028-X

[45] H. Obata, N. Inoue and M. Umebayashi, "Effect of Cd on Plasma Membrane ATPase from Plant Roots Differing in Tolerance to Cadmium," Soil Science \& Plant Nutrition, Vol. 42, No. 2, 1996, pp. 361-366.

[46] A. Janeczko, J. Kościelniak, M. Pilipowicz and S. Lukaszewska, "Protection of Winter Rape Photosystem 2 by 24-Epibrassinolide under Cadmium Stress," Photosynthetica, Vol. 43, No. 2, 2005, pp. 293-298. doi:10.1007/s11099-005-0048-4

[47] S. Hayat, B. Ali, S. A. Hasan and A. Ahmad, "Brassinosteroid Enhanced the Level of Antioxidants under Cadmium Stress in Brassica juncea," Environmental and Experimental Botany, Vol. 60, No. 1, 2007, pp. 33-41. doi:10.1016/j.envexpbot.2006.06.002

[48] S. Hayat, S. A. Hasan, Q. Hayat and A. Ahmad, "Brassinosteroids Protect Lycopersicon esculentum from Cad- 
mium Toxicity Applied as Shotgun Approach," Protoplasma, Vol. 239, No. 1-4, 2010, pp. 3-14. doi:10.1007/s00709-009-0075-2

[49] A. Gayor, P. S. Srivastava and M. Iqbal, "Morphogenic and Biochemical Responses of Bacopa monniera Cultures to Zinc Toxicity," Plant Science, Vol. 143, No. 2, 1999, pp. 187-193. doi:10.1016/S0168-9452(99)00032-1

[50] N. Vaillant, F. Monnet, A. Hitmi, H. Sallanon and A. Coudret, "Comparative Study of Responses in Four Datura Species to Zinc Stress," Chemosphere, Vol. 59, No. 7, 2005, pp. 1005-1013. doi:10.1016/j.chemosphere.2004.11.030

[51] S. Castiglione, C. Franchin, T. Fossat, G. Lingua, P. Torrigiani and S. Biondi, "High Zinc Concentrations Reduce Rooting Capacity and Alter Metallothionein Gene Expression in White Poplar (Populus alba L. cv. Villafranca)," Chemosphere, Vol. 67, No. 6, 2007, pp. 11171126. doi:10.1016/j.chemosphere.2006.11.039

[52] R. K. Tewari, P. Kumar and P. N. Sharma, "Morphology and Physiology of Zinc-Stressed Mulberry Plants," Journal of Plant Nutrition and Soil Science, Vol. 171, 2008, pp. 286-294.

[53] C. C. P. De Magalhaes, D. Cardoso, C. P. D Santos and R. M. Chaloub, "Physiological and Photosynthetic Responses of Synechocystis aquatilis f. Aquatilis (Cyanophyceae) to Elevated Levels of Zinc," Phycology, Vol. 40, No. 3, 2004, pp. 496-504. doi:10.1111/j.1529-8817.2004.03094.x

[54] C. Wang, S. H. Zhang, P. F. Wang, J. Qian, J. Hou, W. J. Zhang and J. Lu, "Excess Zn Alters the Nutrient Uptake and Induces the Antioxidative Responses in Submerged Plant Hydrilla verticillata (L.f.) Royle," Chemosphere, Vol. 76, No. 7, 2009, pp. 938-945.

doi:10.1016/i.chemosphere.2009.04.038

[55] B. Ramakrishna and S. S. R. Rao, "24-Epibrassinolide Alleviated Zinc-Induced Oxidative Stress in Radish (Raphanus sativus L.) Seedlings by Enhancing Antioxidative System," Plant Growth Regulation, Vol. 68, No. 2, 2012, pp. 249-259. doi:10.1007/s10725-012-9713-3

[56] P. Arora, R. Bhardwaj and M. K. Kanwar, "24-Epibrassinolide Induced Antioxidative Defense System of Brassica juncea L. under Zinc Metal Stress," Physiology and Molecular Biology of Plants, Vol. 16, No. 3, 2010, pp. 285-293. doi:10.1007/s12298-010-0031-9

[57] A. Bajguz, "Blockade of Heavy Metals Accumulation in Chlorella vulgaris Cells by 24-Epibrassinolide," Plant Physiology and Biochemistry, Vol. 38, No. 10, 2000, pp. 797-801. doi:10.1016/S0981-9428(00)01185-2

[58] V. A. Vitorello, F. R. Capald and V. A. Stefanuto, "Recent Advances in Aluminium Toxicity and Resistance in Higher Plants," Brazilian Journal of Plant Physiology, Vol. 17, No. 1, 2005, pp. 129-143. doi:10.1590/S1677-04202005000100011

[59] C. Exley, "The Pro-Oxidant Activity of Aluminium," Free Radical Biology and Medicine, Vol. 36, No. 3, 2004, pp. 380-387. doi:10.1016/j.freeradbiomed.2003.11.017

[60] M. A. Akeson, D. N. Munns and R. G. Burau, "Adsorption of $\mathrm{Al}^{3+}$ to Phosphotidylcholine Vesicles," Biochimica et Biophysica Acta (BBA)-Biomembranes, Vol. 986, No. 1,
1989, pp. 33-40. doi:10.1016/0005-2736(89)90269-1

[61] M. Detters, J. P. Servais and E. Wulfert, "Neurotoxic Cations Induce Membrane Rigidifications and Membrane Fusion at Micromolar Concentrations," Biochimica et Biophysica Acta (BBA)-Biomembranes, Vol. 855, No. 2, 1986, pp. 271-276. doi:10.1016/0005-2736(86)90174-4

[62] H. Matsumoto, Y. Senoo, M. Kasai and M. Maeshima, "Response of Plant Root to Aluminum Stress: Analysis of the Inhibition of the Root Elongation and Changes in Membrane Function," Journal of Plant Research, Vol. 109, No. 1, 1996, pp. 99-105. doi:10.1007/BF02344294

[63] M. Ciamporova, "Morphological and Structural Responses of Plant Roots to Aluminium at Organs, Tissue and Cellular Levels," Biologia Plantarum, Vol. 45, No. 2, 2002, pp. 161-171. doi:10.1023/A:1015159601881

[64] B. A. Abdullahi, X. Gu, Q. Gan and Y. Yang, "Brassinolide Amelioration of Aluminium Toxicity in Mung Bean Seedling Growth," Journal of Plant Nutrition, Vol. 26, No. 9, 2003, pp. 1725-1734.

doi:10.1081/PLN-120023278

[65] K. B. Balestrasse, S. M. Gallego and M. L. Tomaro, "Aluminium Stress Affects Nitrogen Fixation and Assimilation in Soybean (Glycine max L.)," Plant Growth Regulation, Vol. 48, No. 3, 2006, pp. 271-281.

[66] B. Ali, S. A. Hasan, S. Hayat, Q. Hayat, S. Yadav, Q. Fariduddin and A. Ahmad, "A Role for Brassinosteroids in the Amelioration of Aluminium Stress through Antioxidant System in Mung Bean (Vigna radiata L. Wilczek)," Environmental and Experimental Botany, Vol. 62, No. 2, 2008, pp. 153-159. doi:10.1016/j.envexpbot.2007.07.014

[67] A. K. Shanker, T. C. Cervantes, H. Loza-Taverac and S. Avudainayagam, "Chromium Toxicity in Plants," Environment International, Vol. 31, No. 5, 2005, pp. 739-753. doi:10.1016/j.envint.2005.02.003

[68] S. P. Choudhary, M. Kanwar, R. Bhardwaj, B. D. Gupta and R. K. Gupta, "Epibrassinolide Ameliorates Cr (VI) Stress via Influencing the Levels of Indole-3-Acetic Acid, Abscisic Acid, Polyamines and Antioxidant System of Radish Seedlings," Chemosphere, Vol. 84, No. 5, 2011, pp. 592-600. doi:10.1016/i.chemosphere.2011.03.056

[69] P. Arora, R. Bhardwaj and M. K. Kanwar, "24-Epibrassinolide Regulated Diminution of Cr Metal Toxicity in Brassica juncea L. Plants," Brazilian Journal of Plant Physiology, Vol. 22, No. 3, 2010, pp. 159-165. doi:10.1590/S1677-04202010000300002

[70] H. Wang, T. Feng, X. Peng, M. Yan, P. Zhou and X. Tang, "Ameliorative Effects of Bassinosteroid on Excess Manganese Induced Oxidative Stress in Zea mays L. Leaves," Agricultural Sciences in China, Vol. 8, No. 9, 2009, pp. 1063-1074. doi:10.1016/S1671-2927(08)60314-4

[71] H. Sze, X. Li and M. G. Palmgren, "Energization of Plant Cell Membranes by $\mathrm{H}^{+}$-Pumping ATPases: Regulation and Biosynthesis," Plant Cell, Vol. 11, No. 4, 1999, pp. 677-689.

[72] K. Kasamo, "Regulation of Plasma Membrane $\mathrm{H}^{+}$-ATPase Activity by the Membrane Environment," Journal of Plant Research, Vol. 116, No. 6, 2003, pp. 517-523. 


\section{doi:10.1007/s10265-003-0112-8}

[73] T. E. Sondergaard, A. Schulz and M. G. Palmgren, "Energization of Transport Processes in Plants. Roles of the Plasma Membrane $\mathrm{H}^{+}$-ATPase," Plant Physiology, Vol. 136, No. 1, 2004, pp. 2475-2482. doi:10.1104/pp.104.048231

[74] Z. Zhang, J. Ramirez, D. Reboutier, M. Brault, J. Trouverie, A. M. Pennarun, Z. Amiar, B. Biligui, L. Galagovsky and J. P. Rona, "Brassinosteroids Regulate Plasma Membrane Anion Channels in Addition to ProtonPumps during Expansion of Arabidopsis thaliana Cells," Plant and Cell Physiology, Vol. 46, No. 9, 2005, pp. 1494-1504. doi:10.1093/pcp/pci162

[75] R. Mittler, "Oxidative Stress, Antioxidants and Stress Tolerance," Trends in Plant Science, Vol. 7, No. 9, 2002, pp. 405-410. doi:10.1016/S1360-1385(02)02312-9

[76] K. Apel and H. Hirt, "Reactive Oxygen Species: Metabolism, Oxidative Stress, and Signal Transduction," Annual Review of Plant Biology, Vol. 55, 2004, pp. 373-399. doi:10.1146/annurev.arplant.55.031903.141701

[77] C. M. Andre, L. Yvan and E. Daniele, "Dietary Antioxidants and Oxidative Stress from a Human and Plant Perspective: A Review," Current Nutrition \& Food Science, Vol. 6, No. 1, 2010, pp. 2-12. doi: $10.2174 / 157340110790909563$

[78] S. Q. Cao, Q. T. Xu, Y. J. Cao, K. Qian, K. An, Y. Zhu, B. Z. Hu, H. F. Zhao and B. Kuai, "Loss of Function Mutations in DET2 Gene Lead to an Enhanced Resistance to Oxidative Stress in Arabidopsis," Physiologia Plantarum, Vol. 123, No. 1, 2005, pp. 57-66. doi:10.1111/j.1399-3054.2004.00432.x

[79] X. J. Xia, Y. J. Wang, Y. H. Zhou, Y. Tao, W. H. Mao, K. Shi, T. Asami, Z. X. Chen and J. Q. Yu, "Reactive Oxygen Species Are Involved in Brassinosteroid-Induced Stress Tolerance in Cucumber," Plant Physiology, Vol. 150, No. 2, 2009, pp. 801-814. doi:10.1104/pp.109.138230

[80] M. Behnamnia, K. M. Kalantari and J. Ziaie, "The Effects of Brassinosteroid on the Induction of Biochemical Changes in Lycopersicon esculentum under Drought Stress," Turkish Journal of Botany, Vol. 33, No. 6, 2009, pp. 417428.

[81] B. Ali, S. Hayat and A. Ahmad, "28-Homobrassinolide Ameliorates the Saline. Stress in Chickpea (Cicer arietinum L.)," Environmental and Experimental Botany, Vol. 59, No. 2, 2007, pp. 217-223.

doi:10.1016/j.envexpbot.2005.12.002

[82] L. M. Mazorra, "Los Brasinoesteroides y su Relación Con la Tolerancia de Plántulas de Tomate (Solanum Iycopersicum L.) Ante el Choque por Temperatura Alta," Ph.D. Thesis, University of Havana, Havana, 2008.

[83] Y. Liu, H. Jiang, Z. Zhao and L. An, "Abscisic Acid Is Involved in Brassinosteroids-Induced Chilling Tolerance in the Suspension Cultured Cells from Chorispora bungeana," Journal of Plant Physiology, Vol. 168, No. 9, 2011, pp. 853-862. doi:10.1016/j.jplph.2010.09.020

[84] S. P. Choudhary, J.-Q. Yu, K. Yamaguchi-Shinozaki, K. Shinozaki and L.-S. Tran, "Benefits of Brassinosteroid Crosstalk," Trends in Plant Science, Vol. 17, No. 10, 2012, pp. 594-605. doi:10.1016/j.tplants.2012.05.012 